\title{
Right ventricle Outflow Tract Acceleration Time: Correlation with Left Ventricular Diastolic Function
}

\begin{abstract}
Liz Andréa Villela Baroncini ${ }^{1}{ }^{*}$, Kenia Urnau ${ }^{1}$, Ana Cristina Camarozano ${ }^{1}$, Daniela de Castro Carmo ${ }^{1}$, Jerônimo Antonio Fortunato ${ }^{1}$, Rubens Zenóbio Darwich ${ }^{1}$

${ }^{1}$ Hospital da Cruz Vermelha - Cruz Vermelha Brasileira- Filial do Estado do Paraná e Instituto Saber e Aprender - Curso de Especialização em Ecocardiografia Transtorácica

*Corresponding Author: Liz Andréa V Baroncini, Hospital da Cruz Vermelha - Cruz Vermelha Brasileira- Filial do Estado do Paraná e Instituto Saber e Aprender - Curso de Especialização em Ecocardiografia Transtorácica, Brazil.E-mail:lizandreabaroncini@hotmail.com

Received date: November 08, 2019; Accepted date: December 22, 2019; Published date: January 3,2020

Citation: Liz Andréa V Baroncini, Kenia U, Ana C Camarozano, Daniela D Carmo, Jerônimo A Fortunato (2019). Right ventricle Outflow Tract Acceleration Time: Correlation with Left Ventricular Diastolic Function.J Clin Imag. Interven Radiology 2(1); Doi: 10.31579/ 2642-1674/08

Copyright: (92020 Liz Andréa V Baroncini, This is an open-access article distributed under the terms of The Creative Commons. Attribution License, which permits unrestricted use, distribution, and reproduction in any medium, provided the original author and source are credited.
\end{abstract}

\begin{abstract}
Background: There are no available data about the measurement of acceleration time at the right ventricle outflow tract (AcT) and its relevance in the analysis of the left ventricular diastolic function (LVDF).

Objective: To correlate AcT with echocardiographic parameters of LVDF.

Method: Eighty-seven patients (58.4 \pm 14.5 years; $52 \%$ women) submitted to transthoracic echocardiogram assessing spectral and tissue Doppler of the transmitral flow and mitral annulus, AcT, left atrial volume (LAV), and pulmonary artery systolic pressure (PASP). Patients with systolic dysfunction of the LV and grades II and III diastolic dysfunction (DD) were excluded. Main analyses were performed using the Spearman's Correlation Coefficient (SCC) and Pearson's Linear Correlation Coefficient (PLCC).

Results: A negative correlation between AcT value and age (PLCC - 0.36; Student's t-test; $\mathrm{p}<0.001$ ) and a positive correlation between AcT and E/A ratio (SCC 0.38; $<<0.001$ ), between AcT and E/e' ratio (SCC 0.26; $\mathrm{p}=0.01$ ), between AcT and $\mathrm{E}$ wave of the mitral flow (PLCC 0.36; $\mathrm{p}=0.001$ ) were found. LAV and PASP did not correlate with AcT. In patients with a normal diastolic function, AcT was higher when compared with the AcT in patients with Grade I DD $(0.150 \pm 0.029 \mathrm{~ms}$ versus $0.127 \pm 0.023 \mathrm{~ms}$; $\mathrm{p}<0.001$; Student's t-test). The threshold suggested in this subgroup of patients was $0.135 \mathrm{~s}$.

Conclusions: The present study correlated, unprecedentedly, AcT with echocardiographic parameters of the LV diastolic function. AcT values lower than $0.135 \mathrm{~s}$ were associated with grade I diastolic dysfunction and higher than $0.135 \mathrm{~s}$ values were associated with normal diastole.
\end{abstract}

Key-words: diastole, Doppler echocardiography, left ventricular dysfunction, pulmonary artery

\section{Running Title: Pulmonary Acceleration Time and Diastolic Function}

\section{Introduction}

Diastole is a complex process of the cardiac cycle, dependent on the active myocardial relaxation, ventricular compliance, ventricular synchrony, ventricular diastolic suction, myocardial viscoelasticity, atrial contraction, pericardial restriction, interaction between right ventricle (RV) and left ventricle (LV) and the erectile function of the coronary arteries [1]. An altered RV-LV interaction leads to a diastolic dysfunction characterized by an increased dependence of the left ventricle filling in relation to the left atrial contraction [2]. Additionally, the diastolic function is affected by clinical factors such as age, systemic arterial hypertension and pulmonary arterial hypertension [3-4].

In this regard, at the transthoracic echocardiography (TTE), the assessment of the left ventricle diastolic function (LVDD) must be performed by integrating several techniques including the analysis of the spectral Doppler of the mitral flow, the tissue Doppler of the mitral annulus, pulmonary veins flow, the estimates of the pulmonary artery systolic pressure (PASP) and of the left atrial volume (LAV)[1]. PASP is most commonly determined by estimating the peak tricuspid regurgitant velocity, not always present, by means of the continuous wave Dopplerp [5], adding the right atrial pressure by assessing the inferior vena cava. An alternate option to estimate the pulmonary arterial pressure is to measure the right ventricle outflow tract acceleration time (AcT), which presented high correlation with PASP in previous studies, with a reference value of $105 \mathrm{~ms}$ [5-7]. Nevertheless, there are no published studies correlating its value with the conventional variables of the LV diastolic function assessed at TTE. Hence, the present study seeks to correlate AcT with the traditionally used variables at ETT to assess the LVDD, among them, E and A waves, E/A ratio, and isovolumetric relaxation time (IVRT) trough spectral Doppler of the mitral flow, septal and lateral e' waves at tissue Doppler of the mitral annulus, E/e' ratio (E/mean between septal and lateral e'), LAV and PASP.

\section{Methods}

This observational and transversal study includes 94 patients, from both genders, any ethnic background, over 18 years of age, from an outpatient cardiology unit of a public hospital, recommended by the assistant physician to undergo transthoracic echocardiogram for any clinical indication. The patients' selection did not follow any statistical criterion, but that of convenience, that is, according to their availability to participate in the research study. For each patient, a protocol form with clinical and echocardiographic parameters was completed. Analyzed demographic data included age, gender, body mass index (BMI), presence of hypertension, diabetes mellitus (DM), dyslipidemia, coronary arterial disease (CAD), history of current or former smoking, and frequent or continuous use of prescribed drugs. Diagnoses for hypertension, DM, 
dyslipidemia, and CAD were recorded in the patients' medical files and/or reported by the patients themselves (referral information data).

Patients underwent a complete bidimensional transthoracic echocardiogram with the Phillips IE 33, Envisor or Vivid E General Electric models. In all acoustic views, all standard measurements and echocardiographic analyses were conducted in each patient and the sonographic analyses were performed by two experienced echocardiographers, holders of echocardiography certificates from the Cardiovascular Imaging Department of the Brazilian Society of Cardiology.

Exclusion criteria included patients with (a) significant valvular heart disease (moderate and severe); (b) prosthetic heart valves; (c) pulmonary emphysema or chronic obstructive pulmonary disease; (d) moderate to severe pulmonary arterial hypertension (PASP > $50 \mathrm{mmHg}$ ); (e) atrial fibrillation or pacemaker rhythm; f) dilated cardiomyopathy or ischemic cardiomyopathy with regional wall motion abnormality or myocardial segmental thickness of left ventricle; (g) LV systolic dysfunction (ejection fraction $<52 \%$ for men and $<54 \%$ for women); (h) grades II and III LVDD; and (i) inappropriate acoustic window for AcT analysis.

In this study, the main echocardiographic variables assessed were: (a) at the transmitral spectral Doppler, the E wave velocity, A wave velocity, E/A ratio and isovolumetric relaxation time (IVRT); (b) from the mitral annular tissue Doppler imaging, septal e' wave velocity, lateral e' wave velocity, mean velocity between septal e' and lateral e'; (c) E/e' ratio (E wave velocity/mean velocity between septal e' and lateral e'); (d) acceleration time at the right ventricle outflow tract (AcT), measured on the short axis view toward the heart base vessels, at the tip of the pulmonary valve leaflet, from the start to the peak of the systolic flow; (e) left atrial volume (LAV) and (f) pulmonary artery systolic pressure (PASP), measured by the tricuspid regurgitation peak velocity, when present (Figures 1 and 2).

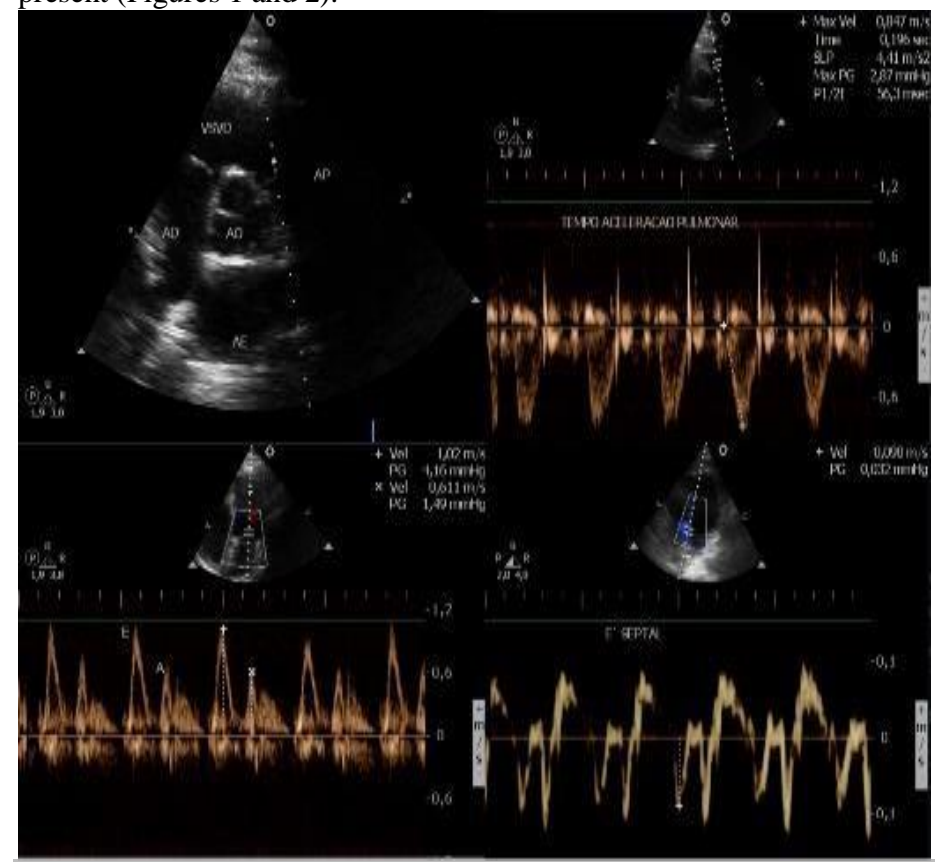

Figure1: Upper left corner: short axis window base vessels with Doppler cursor at the tip of the pulmonary valve leaflets. Upper right corner: measurement of the acceleration time in the right ventricular outflow tract. Lower left corner: Spectral Doppler of the transmittal flow. Right lower corner: Mitral annulus tissue Doppler.
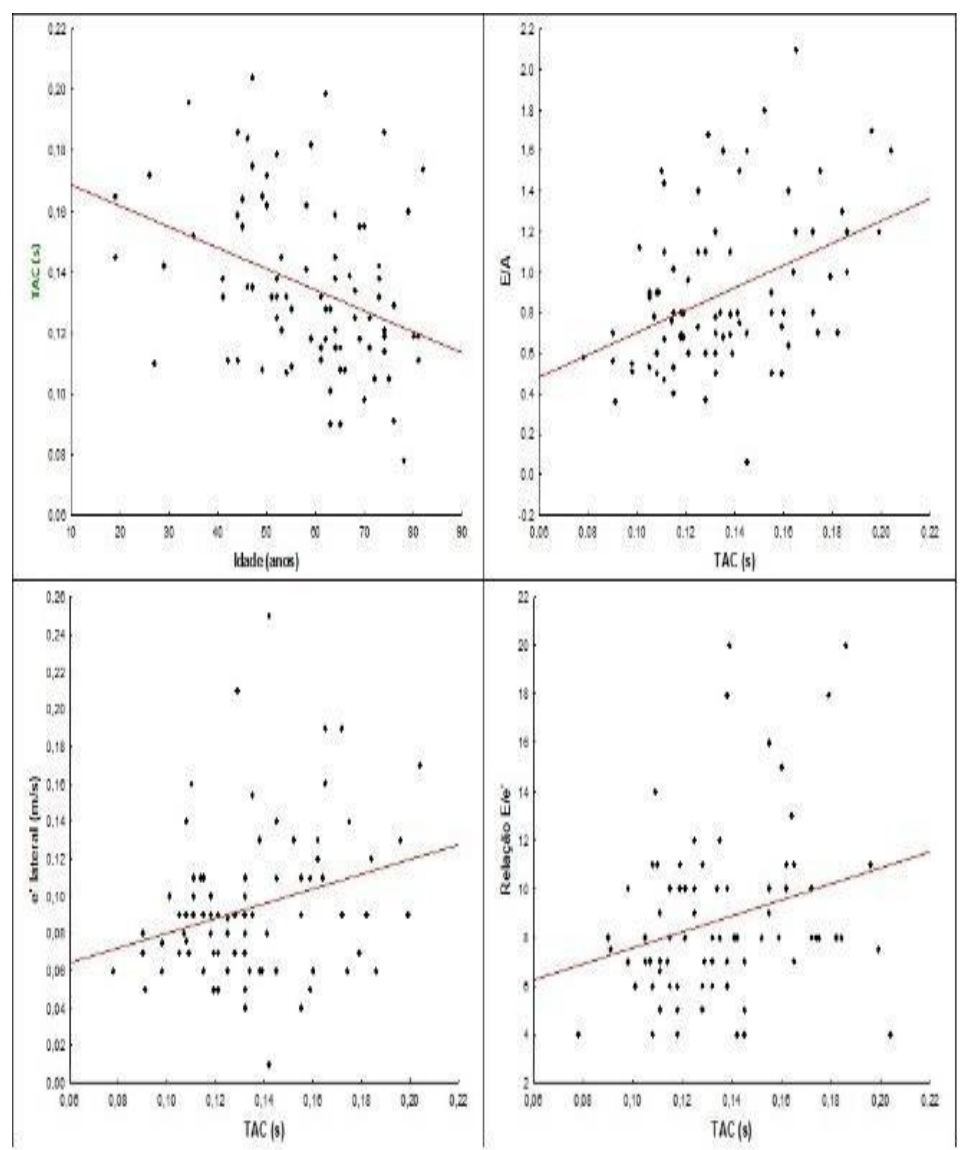

Figure 2. Upper left corner: Correlation between CAT and age (years).Upper right corner: Correlation between TAC and I / A ratio.Lower left corner: correlation between $\mathrm{CT}$ and lateral mitral annulus.Lower right corner: Correlation between TAC and E / e ratio.

\section{Statistical Analysis}

The results obtained were described by means, medians, minimum and maximum values, and standard deviations (quantitative variables) or by frequencies and percentages (categorical variables). To assess the association between two quantitative variables, Pearson's or Spearman's linear correlation coefficient was used. The comparison of two groups in relation to the quantitative variables was performed by the student's' $t$ test for independent samples. The one-way analysis of variance (ANOVA) was used to compare more than two groups. The KolmogorovSmirnov normality test examined whether the variables were normally distributed. Values of $\mathrm{p}<0.05$ indicated statistical significance. To determine an AcT threshold that was associated with the normal diastole versus grade I dysfunction, a ROC curve was adjusted. Data were analyzed with the IBM SPSS Statistics Software 20.0, Armonk, NY: IBM Corp.

\section{Results}

Seven patients, out of the 94 initially selected, were excluded from the study. Final analysis included 87 patients, $58.4 \pm 14.5$ years; 45 $(52 \%)$ women. Clinical characteristics of the studied cohort are listed in Table 1. 
J. Clinical Imaging and Interventional Radiology

\begin{tabular}{|l|l|l|l|}
\hline Variable & & $\mathrm{N}$ & \\
\hline Age (years) & $58.4 \pm 14.5$ & 87 & \\
\hline Gender & \multicolumn{1}{|c|}{ Male } & 42 & $48 \%$ \\
\hline & Female & 45 & $52 \%$ \\
\hline $\begin{array}{l}\text { Systemic arterial } \\
\text { hypertension }\end{array}$ & No & 22 & $30.1 \%$ \\
\hline & Yes & 51 & $69.9 \%$ \\
\hline Diabetes Mellitus & No & 54 & $64 \%$ \\
\hline & Yes & 19 & $26 \%$ \\
\hline Coronary arterial disease & No & 14 & $80.8 \%$ \\
\hline & Yes & 59 & $19.2 \%$ \\
\hline Smoking & No & 73 & $83 \%$ \\
\hline & Yes & 14 & $16 \%$ \\
\hline Body Mass Index $\left(\mathrm{kg} / \mathrm{m}^{2}\right)$ & $27.9 \pm 4.9$ & 81 & \\
\hline
\end{tabular}

Table 1. Clinical basal characteristics of the studied population

Values from the identified echocardiographic variables corroborate those values from the available literature (Table 2).

\begin{tabular}{|l|l|l|l|}
\hline Variable & $\mathrm{N}$ & Mean & $\begin{array}{l}\text { Standard } \\
\text { Deviation }\end{array}$ \\
\hline $\begin{array}{l}\text { Acceleration time in the } \\
\text { pulmonary artery (s) }\end{array}$ & 87 & 0.135 & 0.028 \\
\hline E/A ratio & 87 & 0.894 & 0.382 \\
\hline Septal e' (m/s) & 85 & 0.072 & 0.025 \\
\hline Lateral e' (m/s) & 85 & 0.094 & 0.040 \\
\hline E/e' ratio & 84 & 8.698 & 3.381 \\
\hline Isovolumetric relaxation time (s) & 83 & 0.105 & 0.024 \\
\hline E Wave (m/s) & 87 & 0.619 & 0.208 \\
\hline A Wave (m/s) & 87 & 0.723 & 0.197 \\
\hline Left atrial volume $\left(\mathrm{ml} / \mathrm{m}^{2}\right)$ & 45 & 36.3 & 9.7 \\
\hline $\begin{array}{l}\text { Systolic pressure in the } \\
\text { pulmonary artery }(\mathrm{mmHg})\end{array}$ & 21 & 28.0 & 5.7 \\
\hline
\end{tabular}

Table 2. Echocardiographic variables.

A negative and significant correlation (Spearman's correlation coefficient (SCC) between AcT value and age $(\mathrm{SCC}-0.36 ; \mathrm{p}=0.001)$ and a tendency between AcT value and wave A (SCC $-0.21 ; \mathrm{p}=0.05)$ were observed. Additionally, positive and significant correlations were identified between AcT value and E/A ratio (SCC 0.38; $\mathrm{p}=<0.001$ ), between AcT and lateral e' wave (SCC 0.22; $\mathrm{p}=0.04$ ), between AcT and E/e' ratio (SCC 0.26; $\mathrm{p}=0.01$ ) and between AcT and E wave (SCC 0.36; $\mathrm{p}=0.001$ ). The other variables did not correlate with AcT (Table 3, Figure 3).

\begin{tabular}{|l|l|l|l|}
\hline Variables & n & Correlation Coefficient* & P \\
\hline Age vs BMI (kg/m²) & 86 & -0.04 & 0.735 \\
\hline Age vs E/A Ratio & 85 & -0.52 & $<0.001$ \\
\hline Age vs Septal e' (m/s) & 83 & -0.40 & $<0.001$ \\
\hline Age vs Lateral e' (m/s) & 83 & -0.57 & $<0.001$ \\
\hline Age vs E/e' Ratio & 82 & 0.03 & 0.775 \\
\hline Age vs IVRT (s) & 81 & 0.34 & 0.002 \\
\hline Age vs E Wave (m/s) & 85 & -0.33 & 0.002 \\
\hline Age vs A Wave (m/s) & 85 & 0.49 & $<0.001$ \\
\hline Age vs Left Atrial Volume & 43 & 0.45 & 0.002 \\
\hline Age vs PASP & 21 & 0.39 & 0.082 \\
\hline
\end{tabular}

Table 3. Correlation between age and LV diastolic function. * Spearman's correlation coefficient (E/A, lateral $\mathrm{e}^{\prime}$ and $\mathrm{E} / \mathrm{e}^{\prime}$ ratio) or Pearson's linear correlation coefficient (other variables)

BMI = Body Mass Index IVRT = Isovolumetric Relaxation Time; PASP $=$ Pulmonary Artery Systolic Pressure.
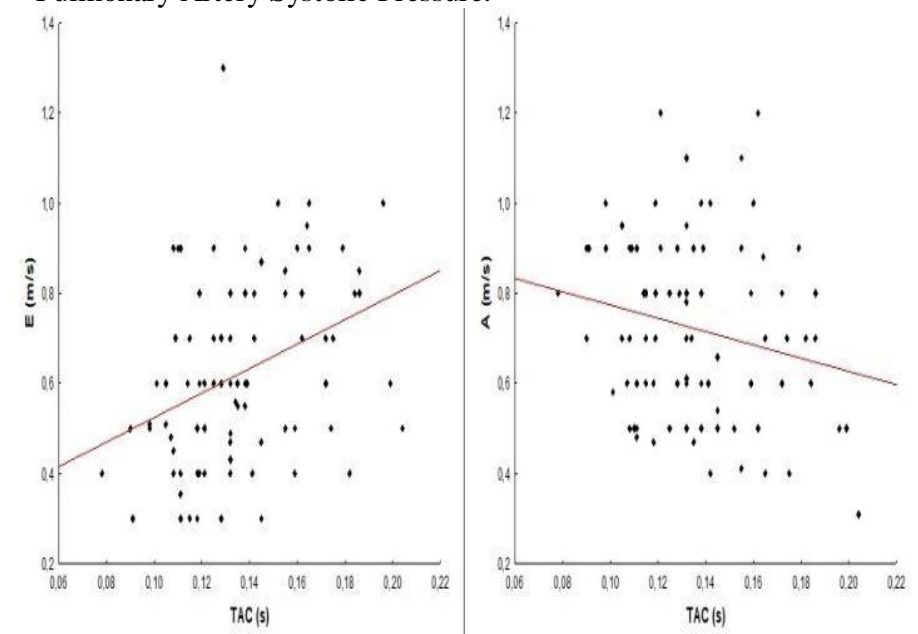
Figure 3: Left side: Correlation between CT and E-wave mitral flow. Right
side: correlation between CT and mitral flow wave A.

Only 5 patients presented AcT values lower than $105 \mathrm{~ms}$ and these values did not correlate with PASP increase or with any other variable (data not shown). AcT value was not influenced by gender, BMI, presence hypertension, DM, dyslipidemia, CAD or smoking (data not shown). Lower AcT values were identified in patients affected by LVDD grade I when compared to patients with preserved LVDD $(0.127 \pm 0.023$ versus $0.150 \pm 0.29 \mathrm{~ms} ; \mathrm{p}<0.001)$. The threshold suggested by the ROC curve adjustment was $0.135 \mathrm{~s}$. Hence, AcT values lower than $0.135 \mathrm{~s}$ were associated with the presence of a LVDD grade I and values higher than 0.135 s with normal diastole, with sensitivity and specificity thresholds estimated in $70.2 \%$ and $70.4 \%$, respectively. (Figure 4 ).

\begin{tabular}{|c|c|c|}
\hline \multirow{2}{*}{ TAC } & \multicolumn{2}{|c}{ DIÁSTOLE } \\
\cline { 2 - 3 } & Normal & DD1 \\
\hline$\geq 0,135$ & 19 & 17 \\
& $70,4 \%$ (especif) & $29,8 \%$ \\
\hline$<0,135$ & 8 & 40 \\
& $29,6 \%$ & $70,2 \%$ (sensib) \\
\hline Total & 27 & 57 \\
\hline
\end{tabular}

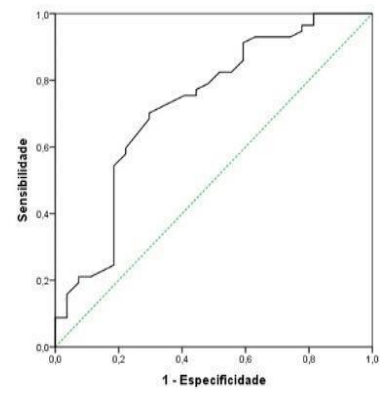

Sensibilidade: probabilidade do TAC ser $<0,135$ dado que a diástole é DD1

Especificidade: probabilidade do $T A C$ ser $\geq 0,135$ dado que a diástole é normal

\section{Figure 4. ROC curve for the value of $\mathrm{CT}$ and left ventricular diastolic} function.

Age presented a negative and significant correlation with E/A ratio (SCC -0.54; $\mathrm{p}<0.001$ ), with lateral e' wave (SCC -0.59 ; $\mathrm{p}<0.001$ ), with septal e' wave (Pearson's correlation coefficient $-\mathrm{PCC}-0.40 ; \mathrm{p}<0.001$ ) and with $\mathrm{E}$ wave $(\mathrm{PCC}-0.34, \mathrm{p}=0.001)$. Age also showed positive and significant correlation with IVRT (PCC $0.38 ; \mathrm{p}=0.001$ ) and A wave (PCC $0.51 ; \mathrm{p}<0.001)$; however, it did not correlate significantly with $\mathrm{E} / \mathrm{e}$ ' ratio $(\mathrm{p}=0.78)($ Table 4$)$. 
(2)

\begin{tabular}{|l|l|l|l|}
\hline Variables & $\mathbf{n}$ & $\begin{array}{l}\text { Correlation } \\
\text { Coefficient* }\end{array}$ & $\mathbf{p}$ \\
\hline AcT (s) vs Age (years) & 85 & -0.36 & $\begin{array}{l}<0.00 \\
1\end{array}$ \\
\hline AcT (s) vs BMI (kg/m²) & 85 & -0.03 & 0.757 \\
\hline AcT (s) vs E/A & 87 & 0.38 & $\begin{array}{l}<0.00 \\
1\end{array}$ \\
\hline AcT (s) vs Septal e' (m/s) & 85 & 0.09 & 0.437 \\
\hline AcT (s) vs Lateral e' (m/s) & 85 & 0.21 & 0.055 \\
\hline AcT (s) vs E/e' Ratio & 84 & 0.26 & 0.019 \\
\hline AcT (s) vs IVRT (s) & 83 & -0.12 & 0.273 \\
\hline AcT (s) vs E Wave (m/s) & 87 & 0.36 & 0.001 \\
\hline AcT (s) vs A Wave (m/s) & 87 & -0.21 & 0.055 \\
\hline $\begin{array}{l}\text { AcT (s) vs Left Atrial } \\
\text { Volume }\end{array}$ & 45 & 0.05 & 0.731 \\
\hline AcT (s) vs PASP & 21 & 0.06 & 0.793 \\
\hline
\end{tabular}

Table 4. Correlation between the acceleration time (AcT) in the pulmonary artery and LV diastolic function variables. * Spearman's correlation coefficient (E/A, lateral $\mathrm{e}^{\prime}$ and $\mathrm{E} / \mathrm{e}^{\prime}$ ratio) or Pearson's linear correlation coefficient (other variables).

$\mathrm{BMI}=$ Body Mass Index; IVRT = Isovolumetric Relaxation Time; PASP = Pulmonary Artery Systolic Pressure.

\section{Discussion}

The present study presented unprecedent correlation of AcT absolute values with echocardiographic variables representatives of LV diastolic function. Concomitantly, the same values have shown to change with age increase. Previous studies report that LV diastolic function changes and progresses with age[11-12], independent of a LV preserved systolic function, and may even lead to heart failure with normal LV ejection fraction[13-15] Similarly, the systolic pressure in the pulmonary artery progressively increases with age both at rest and during exercise[16-17]. AcT values identified in this study follow the same alterations. The rigid exclusion criteria applied enabled the assessment of the LV diastolic function and AcT without the influence of other factors, such as the presence of a significant pulmonary arterial hypertension, systolic dysfunction or advanced grades of LV diastolic dysfunction, which might lead to different interpretations. These same criteria determined homogeneity in the studied cohort. Hence, it was possible to observe that correlation of E/A ratio at mitral spectral Doppler decreases with age (following the decrease of wave $\mathrm{E}$ velocity and increase of $\mathrm{A}$ wave). Values of septal and lateral e' waves of the mitral annulus at tissue Doppler also decreased. These findings corroborate former studies involving a larger cohort of patients[18-19]. Similarly, AcT values followed the same values obtained for the LV diastolic function variables used in this study: the age increase correlated with AcT lower values, the lower AcT values correlated significantly with lower values of the E/A ratio, with lower values of $\mathrm{E}$ and lateral e' waves. However, E/e' ratio presented a positive correlation with AcT value, specifically, lower AcT values correlated with lower values of the E/e' ratio. This finding may be accounted for by analyzing the behavior of lateral and septal e' waves that decrease with age (about 10 to 15 years earlier) when compared with $\mathrm{E}$ wave of spectral Doppler, which decreases at a late stage, as described by Kadappu KK et al. In the present study, a stronger negative correlation of age with septal and lateral e' waves in relation to E wave of the spectral Doppler was observed. Hence, in an early stage of the diastolic dysfunction, without the increase of the filling pressures of the left atrium (LA), the E/e' ratio is still low, as is the AcT value, since e' waves decrease more sharply than E wave in this phase. Similar explanation is provided for the lack of correlation between IVRT and Act values. It is known that IVRT prolongs with age; however, when there is an increase in the filling pressures, IVRT shortens ${ }^{21}$. The selected severe exclusion criteria also enabled assessment of AcT in quasi-normality conditions. PASP mean value was $28 \mathrm{mmHg}$ and its maximum value was $40 \mathrm{mmHg}$, values considered to be within normality for the age range in the studied population[22]. Hence, a correspondence between AcT and PASP would only be expected in the presence of significant pulmonary hypertension, which was not the purpose of this study. However, when patients with a normal LV diastolic function and those with grade I diastolic dysfunction were compared, the latter presented lower AcT values, suggesting an increase in the pulmonary arterial pressure in this group, although still within their normal values. AcT values below $105 \mathrm{~ms}$ are considered abnormal or reveal an increase in the pulmonary arterial pressure (PAH) [23]. Conversely, by excluding patients with a significant pulmonary arterial hypertension from the studied cohort, AcT values below $105 \mathrm{~ms}$ were not expected. However, in an unprecedent way, it was possible to identify an alteration in AcT value in patients without a significant PAH, with an initial alteration of the LV diastolic function when compared with a preserved LV diastolic function. Some limitations of this study include the small number of participants, lack of data about the size and function of the right chambers and lack of analysis of the intra- and inter-observer measurement variability in relation to AcT, as errors may occur, considering that AcT values are affected by heart rates, cardiac output, RV systolic function and technical difficulties such as the angle of the ultrasonic beam[5].

\section{Conclusions}

The present study correlated significantly and unprecedentedly AcT with echocardiographic parameters of the LV diastolic function, presenting lower values in individuals with grade I diastolic dysfunction. The threshold suggested by the ROC curve was $0.135 \mathrm{~s}$, with AcT values lower than $0.135 \mathrm{~s}$ associated with grade I diastolic dysfunction and higher than $0.135 \mathrm{~s}$ values associated with normal diastole.

\section{References}

1. Diretrizes das indicações da Ecocardiografia. Avaliação da função e estrutura ventricular esquerda. Sociedade Brasileira de Ecocardiografia. Arq Bras Cardiol 2009; 93(supl.3):e265-e266.

2. Bossone E, D'Andrea A, D'Alto M, Citro R, Argiento P, et al (2013).Echocardiography in pulmonar artery hypertension: from diagnosis to prognosis. J Am Soc, Echocardiogr;26:1-14.

3. Mitter SS, Shah SJ, Thomas JD.(2017). A test in context. E/A and E/e' to asses diastolic dysfunction and LV filling pressure. J Am Coll Cardiol;69(1):1451-1464.

4. Rosa EC, Moysés VA, Rivera I, Sesso RC, Kohlmann N, et al (2002). Left ventricular diastolic function in essential hypertensive patients. Influence of age and left ventricular geometry. Arq Bras Cardiol;78:472-477.

5. Yared K, Noseworthy P, Weyman AE, McCabe E, Picard MH, et al (2011). Pulmonary artery acceleration time provides an accurate estimate of systolic pulmonary arterial pressure during transthoracic echocardiography. J Am Soc Echocardiogr;24:687692.

6. Lopez-Candales A, Eleswarapu A, Shaver J, Edelman K, Gulyasy B, et al(2010). Right ventricular outflow tract spectral signal: a useful marker of right ventricular systolic performance and pulmonary hypertension severity. Eur J Echocardiogr; 11:509-515.

7. Grapsa J, Tzemos N.( 2018). Echocardiography in pulmonary hypertension: current evidence and future perspectives. Continuing Cardiology Education;3:4.

8. Lang RM, Badano LP, Mor-Avi V, Afilalo J, Armstrong A, et al (2015). Recommendations for cardiac chamber quantification by echocardiography in adults: an update from the American Society of Echocardiography and the European Association of Cardiovascular Imaging. J Am Soc Echocardiogr;28:1-39 e14. 
9. DiLorenzo MP, Bahtt SM, Mercer-Rosa L.(2015). How best to assess right ventricular function by echocardiography. Cardiol Young;25:1473-1481.

10. Rudski LG, Lai WW, Afilalo J, Hua L, Handschumacher et al (2010) . Diretrizes para avaliação ecocardiográfica do coração direito em adultos: um informe da Sociedade Americana de Ecocardiografia. Aprovado pela Associação Européia de Ecocardiografia (registrada pela Sociedade Européia de Cardiologia), e pela Sociedade Canadense de Ecocardiografia. J Am Soc Echocardiogr;23:685-713.

11. Campbell DJ, Somaratne JB, Jenkins AJ, Prior DL, Yii et al (2012) . Diastolic dysfunction of aging is independent of myocardial structure but associated with plasma advanced glycation endproduct levels. PLoS ONE;7(11):e49813.

12. Carvalho JC, Farand P, Do HD, Brochu MC, Bonenfant F, et al (2013). Effect of age and sex on echocardiographic left ventricular diastolic function parameters in patients with preserved ejection fraction and normal valvular function. Cardiol J;20:513-518.

13. Garvan C. Kane, Barry L. Karon, Douglas W. Mahoney, Margaret M. Redfield, Veronique L. Roger. et al (2011). Progression of Left Ventricular Diastolic Dysfunction and Risk of Heart Failure. American Medical Association;8;24-31.

14. Aziz F, TK LA, Enweluzo C, Dutta S, Zaeem M. (2013). Diastolic heart failure: a concise review. J Clin Med Res;5:327-334.

15. Zakeri R, Cowie MR. (2018).Heart failure with preserved ejection fraction: controversies, challenges and future directions. Heart;0:18.
16. Kane GC, Sachdev A, Villarraga HR, Ammash NM, Oh JK, et al (2016).Impact of age on pulmonary artery systolic pressures at rest and with exercise. Echo Res Pract;3:53-61.

17. Mahjoub H, Levy F, Cassol M, Meimoun P, Peltier M, et al (2009). Effects of age on pulmonary artery pressure at rest and during exercise in normal adults. Eur J Echo;10:635-640.

18. Parick JD, Hollignsworth KG, Wallace D, Biamire AM, MacGowan GA. (2016) Normal Age-related changes in left ventricular function: Role of after load and subendocardial dysfunction. Intern J Cardiol;223;306-312.

19. Studart PCC, Belém LHJ, Rabischoffisk A, Nogueira AC. (2006). The tissue doppler in the evaluation of the left ventricle diastolic function: its value in the detection of the early alterations and the understanding of the evolution of the dysfunction with normal systolic function. Rev SOCERJ;19:232-238.

20. Kadappu KK, Thomas L. (2015).Tissue Doppler imaging in echocardiography: value and limitations. Heart, Lung and Circulation;24:224-233.

21. Zhang W, Kovács SJ (2009). The age dependence of left ventricular filling efficiency. Ultrasound Med Biol;35:1076-1085.

22. Granstam S-O, Björklund E, Wikström G, Roos MW (2013). Use of echocardiographic pulmonary acceleration time and estimated vascular resistance for the evaluation of possible pulmonary hypertension. Cardiovascular Ultrasound;11:17.

23. Marra AM, Benjamin N, Ferrara F, Vriz O, D’Alto M, et al (2017 ). Reference ranges and determinants of right ventricle outflow tract acceleration time in healthy adults by two-dimensional echocardiography. 33(2):219-226 